\title{
GROWTH AND CHARACTERIZATION OF EPSOMITE SINGLE CRYSTALS DOPED WITH KCI FROM LOW TEMPERATURE AQUEOUS SOLUTIONS
}

\author{
S. FERDOUS AND J. PODDER* \\ Department of Physics, Bangladesh University of Engineering \& Technology \\ Dhaka-1000, Bangladesh
}

\begin{abstract}
Highly transparent and well faceted large size epsomite single crystals have been grown in pure form and doped with $\mathrm{KCl}$ from aqueous solutions by slow cooling and isothermal evaporation method. The optical quality of the epsomite improves on doping by $\mathrm{KCl}$. Mass growth rates were found to increase with doping of lower concentrations of $\mathrm{KCl}$ and then decreases with the higher concentration of $\mathrm{KCl} . \mathrm{KCl}$ doped epsomite crystal reveals that structures are slightly distorted due to adsorption of $\mathrm{Cl}^{-}$ion into the crystal lattice. DC conductivity along the growth axis for all of the grown crystals increases with temperature in the range of 25 to $70{ }^{\circ} \mathrm{C}$ and also increases with the $\mathrm{KCl}$ concentration. Dielectric constant is found to be almost independent of frequency up to range of $10^{6} \mathrm{~Hz}$. The dielectric studies show the suitability of these grown crystals for optoelectronic applications.
\end{abstract}

\section{INTRODUCTION}

Crystallization of heptahydrate sulphate material such as epsomite $\left(\mathrm{MgSO}_{4} .7 \mathrm{H}_{2} \mathrm{O}\right)$ of high purity has become an important field of research for both academic interest and industrial applications in various areas like medical, agricultural and chemical industry ${ }^{(1-3)}$. The epsomite is included in a group of heptahydrate sulphate with the general formula $\mathrm{RSO}_{4} \cdot 7 \mathrm{H}_{2} \mathrm{O}(\mathrm{R}=\mathrm{Mg}, \mathrm{Zn}, \mathrm{Ni}){ }^{(4)} \cdot \mathrm{MgSO}_{4} \cdot 7 \mathrm{H}_{2} \mathrm{O}$, as a source of $\mathrm{Mg}^{2+}$ ions has wide application in medical (like acute management of cardiac arrhythmia, migraine attacks, spasms in cerebral blood vessels) and agricultural industry (as fertilizer) ${ }^{(2-3)}$. The crystal structure of $\mathrm{MgSO}_{4} \cdot 7 \mathrm{H}_{2} \mathrm{O}$ is orthorhombic. During industrial crystallization, the size and shape of the crystal plays an important factor, since the undesirable habits such as plate like or needle like causes the problems of separating, washing or drying ${ }^{(5)}$. The physical properties such as packing density, agglomeration and re-dissolution mainly depend on the shape of the crystal. The pure epsomite crystals have been grown at low temperature from aqueous solutions ${ }^{(6-8)}$. The presence of the foreign particles in the growth media has long been recognized in changing the growth habits of crystals ${ }^{(9-10)}$ Jibbouri et al ${ }^{(9)}$ presented the influence of different additives $\left(\mathrm{KCl}, \mathrm{K}_{2} \mathrm{SO}_{4}, \mathrm{NaCl}\right.$ and $\left.\mathrm{MgCl}_{2}\right)$ on the crystallization kinetics of epsomite. They found that the impurities exert influence on the saturation and super-saturation limit. Ramalingom et al. ${ }^{(11)}$ have studied the urea doped epsomite crystal at low temperature by slow cooling technique. They found that the addition of urea in the mother solution of epsomite increased the metastable zone width and the structure of the epsomite crystals also changed from orthorhombic into tetragonal. From technological and application point of view, in the present study, an attempt has been made to improve the quality of the epsomite crystal by adding $\mathrm{KCl}$ as impurities and to see the influence of impurities on the growth kinetics.

\section{EXPERIMENTAL \\ Growth of single crystals}

Analar grade magnesium sulphate heptahydrate, $\mathrm{KCl}$ and distilled water were used in the crystallization process. The solubility study of epsomite was performed in water

\footnotetext{
* Corresponding author
} 
solvent. The solubility was found to increase almost linearly with the increase of temperature and have a positive coefficient of solubility. Using the solubility data, a saturated solution of the epsomite compound was prepared and allowed to evaporate at room temperature. The pure magnesium sulphate seed crystals were prepared by the conventional isothermal evaporation method. Colorless and transparent crystals were harvested within 15 days under the isothermal evaporation process. The harvested crystals were recrystallized repeatedly to achieve good quality. $\mathrm{KCl}$ was added with epsomite as a dopant material with $0.1,0.2,0.4,0.6,1.0$ and 1.6 molar concentrations. In slow cooling process, crystallization was initiated by decreasing the temperature of the solution at a cooling rate of $0.1{ }^{0} \mathrm{C}$ per day. For natural evaporation process, the crystallizers were covered with perporated polyethylene sheet and kept in a dust free chamber. Pure and $\mathrm{KCl}$ doped $\mathrm{MgSO}_{4} \cdot 7 \mathrm{H}_{2} \mathrm{O}$ crystals were harvested after a period of 3 to 4 weeks.

\section{Characterization}

The infrared spectra of all the grown crystals were recorded by $\mathrm{KBr}$ pellet technique at room temperature in the wave number of 4000 to $400 \mathrm{~cm}^{-1}$. X-ray diffraction studies were carried out using a Shimadzu X-ray Diffractometer with MoK $\alpha$ radiation $\left(\lambda=0.7093 \mathrm{~A}^{\circ}\right)$ with an operating voltage $30 \mathrm{kV}$ and current $20 \mathrm{~mA}$. Scanning rate was maintained at $1^{\circ}$ per minute. The DC conductivity measurements were carried out on the grown crystals by two probe method in the temperature range of $25 \sim 70^{\circ} \mathrm{C}$. Transparent crystals with the dimensions of $8 \mathrm{~mm} \times 6 \mathrm{~mm} \times 2 \mathrm{~mm}$ were cut into a rectangular size and surfaces were coated with silver paint to give good electrical contact between the electrodes. Keithley electrometer was used to measure the current in the samples. The samples, electrodes, leads wires etc. were all well insulated to avoid stray current. The field is applied to perpendicular to c-axis. In this experiment, the applied voltage was kept at 80 volt.

\section{RESULTS AND DISCUSSION}

Growth rates of the crystal

Mass growth rates of the grown crystals were determined by weighing method ${ }^{(12)}$. The seed crystals of pure $\mathrm{MgSO}_{4} \cdot 7 \mathrm{H}_{2} \mathrm{O}$ were placed in $\mathrm{KCl}$ doped $\mathrm{MgSO}_{4} .7 \mathrm{H}_{2} \mathrm{O}$ solution in a petri-dish and then petri dish was kept in a dust free glass chamber. The weights of the growing crystals were recorded for every 24 hours by a digital balance. After four weeks, the crystals were collected from the solution. The growth rates with respect to the initial mass, $G_{g}$, is calculated as $\mathrm{Gg}=\left(m-m_{o}\right) /\left(m_{o} \Delta t\right)$, where, $m_{o}$ is the initial mass, $\mathrm{m}$ is the finial mass, and $\Delta t$ is the growth time.

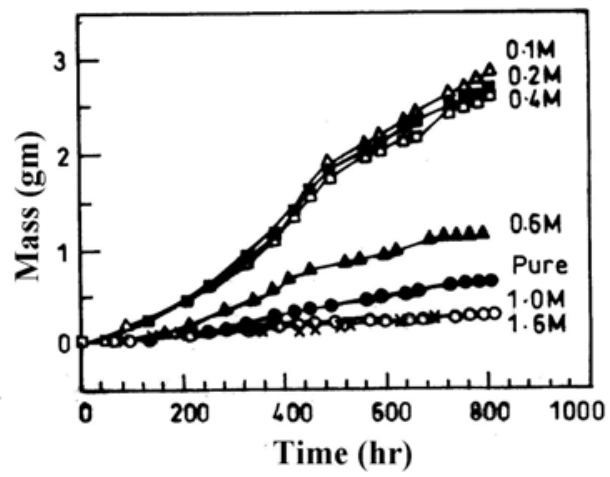

Fig. 1. Mass growth of the pure and doped crystals. 
Mass growth rates of seven different samples are presented in Fig. 1. It was observed that the mass growth rate increases initially to a certain limit of $\mathrm{KCl}$ concentration $(0.1 \mathrm{M})$ and then decreases with the increase of $\mathrm{KCl}$ molar concentration. Highly transparent and well faceted large size single crystals were grown by isothermal evaporation process. The addition of $\mathrm{KCl}$ increased the quality of the crystals by chemical complexion of trace heavy metal ions like $\mathrm{Cd}, \mathrm{Zn}, \mathrm{Co}, \mathrm{Sb}$ etc. present in the solutions by $\mathrm{Cl}^{-}$ion and thus the complex metal ion cannot get into the crystal lattice.
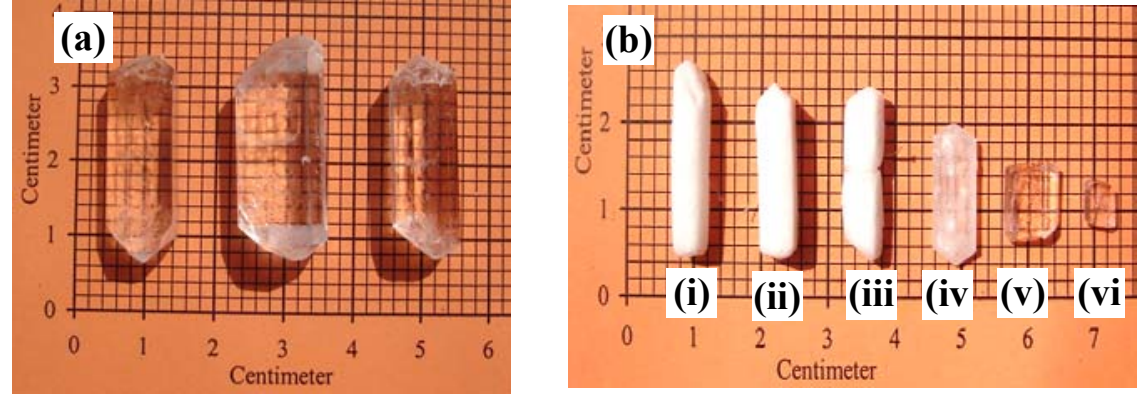

Fig. 2. (a) Single crystals of $0.4 \mathrm{M} \mathrm{KCl}$ doped $\mathrm{MgSO}_{4} \cdot 7 \mathrm{H}_{2} \mathrm{O}$, (b) The order of transparency of the single crystals lost due to drying in desiccators (i) $0.1 \mathrm{M} \mathrm{KCl}$ (ii) $0.2 \mathrm{M} \mathrm{KCl}$ (iii) $0.4 \mathrm{M} \mathrm{KCl}$ (iv) 0.6 $\mathrm{M} \mathrm{KCl}(\mathrm{v}) 1.0 \mathrm{M} \mathrm{KCl}$ (vi) $1.6 \mathrm{M} \mathrm{KCl}$

\section{Influence of $\mathrm{KCl}$}

From the application point of view, sustainability of these crystals in adverse environment (especially in the dry and hot atmosphere) has been studied. For testing the effect of dry weather, the pure $\mathrm{MgSO}_{4} \cdot 7 \mathrm{H}_{2} \mathrm{O}$ crystals were kept in a desiccator containing silica gel. After $2 \sim 3$ days the pure $\mathrm{MgSO}_{4} \cdot 7 \mathrm{H}_{2} \mathrm{O}$ crystals were observed milky-white colour. The crystals became softer but their shape remained unchanged. The grown crystals were completely opaque and lost their transparency, shown in Figure 2 (b). The changes in their transparency and softness are due to the absorption of crystalline water by the silica gel in the dessicator. It was found that $0.1,0.2,0.4 \mathrm{M} \mathrm{KCl}$ doped crystals lost their transparency fully, $0.6 \mathrm{M}$ lost their transparency partially and for higher concentration $(1.6 \mathrm{M})$ crystals remained unchanged. This implies that $\mathrm{Cl}^{-}$ion absorbed into the crystal lattice and the presence of higher concentration of $\mathrm{Cl}^{-}$ion in the crystals is the cause of their unchanged physical properties. The pure $\mathrm{MgSO}_{4} .7 \mathrm{H}_{2} \mathrm{O}$ crystals as well as doped crystals of lower concentration of $\mathrm{KCl}$ are not stable in the dry environment.

\section{Infrared Spectroscopy}

The specified bonds are identified by the corresponding wavenumber and the band assignments are mentioned in the spectra (Fig.3). The absorption band at $550 \mathrm{~cm}^{-1}$ corresponds to $\mathrm{SO}_{4}{ }^{2-}$ bending vibration. The band at around $650 \mathrm{~cm}^{-1}$ represents the presence of $\mathrm{Cl}^{-1}$ ion. In the spectrum, the presence of chlorine is very clearly identified and the peak area corresponds to $\mathrm{Cl}^{-}$ion is increasing with the increase of $\mathrm{KCl}$ molar concentration. It seems that $\mathrm{Cl}^{-}$ion is adsorbed into the lattice sites. The absorption band at $1050 \mathrm{~cm}^{-1}$ is assigned for the $\mathrm{SO}_{4}{ }^{2-}$ stretching vibration. Absorption at around $1600 \mathrm{~cm}^{-1}$ may be assigned to bending vibration of water molecule. The band at around $3300 \mathrm{~cm}^{-1}$ is assigned to $\mathrm{O}-\mathrm{H}$ stretching vibration of water. 

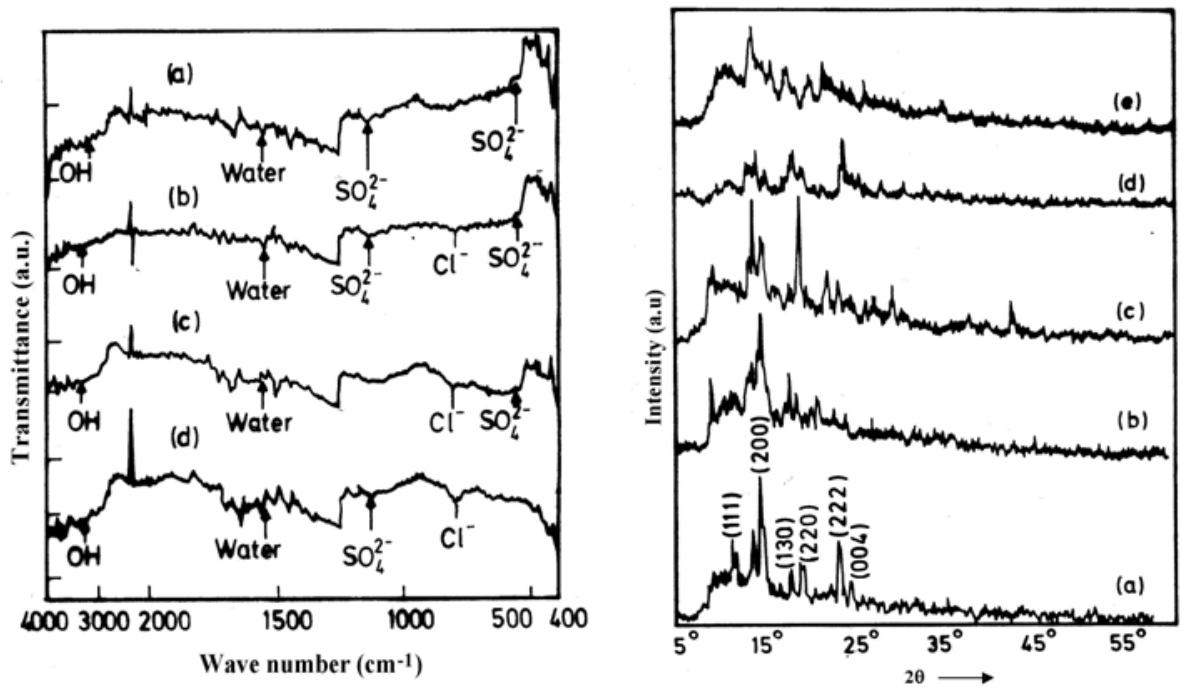

Fig. 3. IR spectroscopy (a) pure $\mathrm{MgSO}_{4} \cdot 7 \mathrm{H}_{2} \mathrm{O}$, (b) $0.1 \mathrm{M} \mathrm{KCl}$ doped, (c) $0.2 \mathrm{M} \mathrm{KCl}$ doped, (d) $0.6 \mathrm{M}$

Fig. 4. X-ray diffraction patterns (a) pure $\mathrm{MgSO}_{4} .7 \mathrm{H}_{2} \mathrm{O}$, (b) $0.1 \mathrm{M} \mathrm{KCl}$ doped, (c) $0.2 \mathrm{M}$ $\mathrm{KCl}$ doped, (d) $0.4 \mathrm{M} \mathrm{KCl}$ doped and (e) $0.6 \mathrm{M}$ $\mathrm{KCl}$ doped $\mathrm{MgSO}_{4} \cdot 7 \mathrm{H}_{2} \mathrm{O}$

\section{X-ray diffraction}

$\mathrm{X}$-ray diffraction patterns for the powdered samples are presented in Fig. 4. From the X-ray diffraction pattern the respective data viz. $2 \theta_{\text {expt, }}$ and relative intensity values for the corresponding hkl planes are presented in Table 1. The X-ray diffraction pattern of the pure and doped $\mathrm{MgSO}_{4} \cdot 7 \mathrm{H}_{2} \mathrm{O}$ single crystals differed in their relative intensities and in the lattice spacing of the crystals. These values are matched well with the ASTM standard values. The reflection peaks are indexed and the deviation in $2 \theta$ i.e. $\Delta 2 \theta=2 \theta_{\text {exp }}-2 \theta_{\text {cal }}$ for the experimental and calculated values are given in Table 1 . The change in $2 \theta$ values suggest that the structures are slightly distorted in comparison to the pure crystal. This may be attributed to the strain on the lattice by the adsorption of $\mathrm{Cl}^{-}$impurities. For pure sample, the deviation in $2 \theta$ values may be due to the presence of natural impurities in the solutions. 
Table. 1.

Indexed powder diffraction data for pure and $\mathrm{KCl}$ doped $\mathrm{MgSO}_{4} \cdot 7 \mathrm{H}_{2} \mathrm{O}$

\begin{tabular}{|c|c|c|c|c|c|c|}
\hline \multicolumn{2}{|r|}{ Samples } & (hkl) & $2 \theta_{\text {cal }}\left({ }^{0}\right)$ & $\mathbf{I} / \mathbf{I}_{\mathbf{0}} \%$ & $2 \theta_{\exp }\left({ }^{0}\right)$ & $\Delta 2 \theta\left(^{\circ}\right)$ \\
\hline \multirow{7}{*}{\multicolumn{2}{|c|}{$\mathrm{MgSO}_{4} \cdot 7 \mathrm{H}_{2} \mathrm{O}$}} & 111 & 11.298 & 55 & 11.6 & +0.302 \\
\hline & & 002 & 12.554 & 35.15 & 12.600 & +0.046 \\
\hline & & 200 & 15.710 & 100 & 14.560 & -1.150 \\
\hline & & 130 & 17.424 & 35 & 18.100 & +0.676 \\
\hline & & 220 & 18.885 & 39 & 19.150 & +0.265 \\
\hline & & 222 & 22.746 & 53 & 23.350 & +0.604 \\
\hline & & 004 & 25.183 & 28 & 24.840 & -0.343 \\
\hline \multirow{28}{*}{ 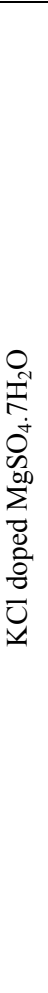 } & \multirow{7}{*}{$0.1 \mathrm{M}$} & 111 & 11.298 & 45 & 11.350 & +0.052 \\
\hline & & 002 & 12.554 & 68.65 & 13.600 & +1.046 \\
\hline & & 200 & 15.710 & 100 & 14.750 & -0.967 \\
\hline & & 130 & 17.424 & 57 & 17.800 & -0.376 \\
\hline & & 220 & 18.885 & 42 & 18.750 & -0.135 \\
\hline & & 222 & 22.746 & 31 & 22.850 & +0.104 \\
\hline & & 004 & 25.183 & 29 & 24.210 & -0.973 \\
\hline & \multirow{7}{*}{$0.2 \mathrm{M}$} & 111 & 11.298 & 43.27 & 11.200 & -0.098 \\
\hline & & 002 & 12.554 & 59.4 & 12.5 & -0.054 \\
\hline & & 200 & 15.710 & 62.2 & 16.1 & +0.383 \\
\hline & & 130 & 17.424 & 40.6 & 17.8 & +0.376 \\
\hline & & 220 & 18.885 & 100 & 18.95 & +0.065 \\
\hline & & 222 & 22.746 & 49.3 & 22.300 & -0.446 \\
\hline & & 004 & 25.183 & 1.65 & 24.900 & -0.283 \\
\hline & \multirow{7}{*}{$0.4 \mathrm{M}$} & 111 & 11.298 & 3208 & 11.500 & +0.202 \\
\hline & & 002 & 12.554 & 59.87 & 12.850 & +0.296 \\
\hline & & 200 & 15.710 & 46.05 & 15.000 & -0.717 \\
\hline & & 130 & 17.424 & 80.20 & 18.00 & +0.567 \\
\hline & & 220 & 18.885 & 52.63 & 19.00 & -0.115 \\
\hline & & 222 & 22.746 & 100 & 23.600 & +0.854 \\
\hline & & 004 & 25.183 & 44.7 & 24.800 & -0.383 \\
\hline & \multirow{7}{*}{$0.6 \mathrm{M}$} & 111 & 11.298 & 3.63 & 11.250 & -0.048 \\
\hline & & 002 & 12.554 & 3.01 & 13.6 & +1.406 \\
\hline & & 200 & 15.710 & 2.56 & 15.95 & +0.233 \\
\hline & & 130 & 17.424 & 2.30 & 17.79 & +0.366 \\
\hline & & 220 & 18.885 & 2.20 & 18.60 & -0.285 \\
\hline & & 222 & 22.746 & 1.80 & 22.80 & +0.054 \\
\hline & & 004 & 25.183 & 1.65 & 24.90 & -0.283 \\
\hline
\end{tabular}

\section{DC conductivity}

A graph of DC conductivity vs. temperature is plotted in Fig. 5. It is found that conductivity increases exponentially with temperature and also with the $\mathrm{KCl}$ concentrations. Conductivity is found in the order of $10^{-7} \mathrm{mho} / \mathrm{m}$. At low temperature region, conductivity is expected due to the presence of weakly attached impurities and vacancies in the crystal lattice. At high temperature region, the attached water molecule is lost and fracture is developed and conductivity is caused mainly for intrinsic defects. 


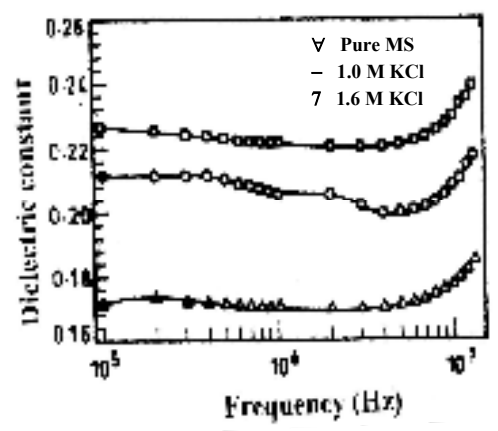

Fig. 5. Conductivity $(\sigma)$ as a function of $1 / \mathrm{T}$

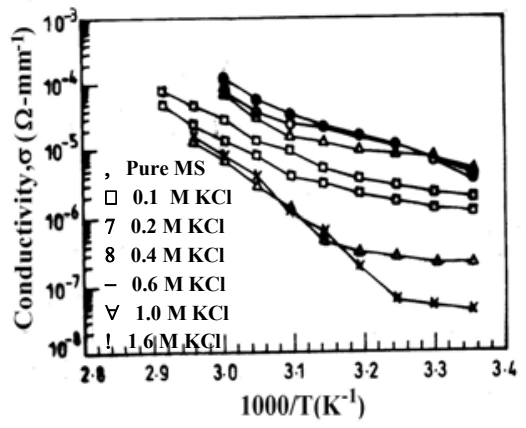

Fig. 6. Dielectric constant as a function of frequency for pure and doped crystals.

\section{Dielectric constant and dielectric loss}

The study of dielectric constant and dielectric losses as a function of frequency is performed to see the polarization mechanism in the samples. Dielectric studies on the grown epsomite crystal have been carried out for various frequencies at room temperature. The samples of dimension $8 \mathrm{~mm} \times 6 \mathrm{~mm} \times 2 \mathrm{~mm}$ were used for dielectric studies. The dielectric constant $\left(\varepsilon^{\prime}\right)$ and dielectric loss $\left(\varepsilon^{\prime \prime}\right)$ were calculated from $\varepsilon^{\prime}=$ $\mathrm{Cd} / \varepsilon_{0} \mathrm{~A}$ and $\quad \varepsilon^{\prime \prime}=\varepsilon^{\prime} \mathrm{D}$, where $\varepsilon_{0}$ is the permittivity of free space. The frequency Vs $\varepsilon^{\prime}$ and frequency Vs $\tan \delta$ are shown in Figures 6 and 7. The dielectric constant is found almost constant up to the frequency $10^{6} \mathrm{~Hz}$ and then increases non-linearly with the increase of frequency. It was also observed that dielectric constant decreases as the concentration of $\mathrm{KCl}$ increases. The dielectric constant is contributed due to space charge polarization. The dielectric loss factor for all the samples decreases as the frequency increases. At low frequencies, the dielectric loss was found to be large. This indicates that the frequency of the electric field is equal to that of natural frequency of bounded charge, which tends to oscillate the molecules with large energy. Due to the presence of damping forces of solids, dipole energy is quickly dissipated resulting in large radiation of electrical energy. Increase of dielectric loss is attributed to ionic polarization and oscillation of dipoles. At higher frequencies, the dielectric loss is relatively low due to the frequency of the electric wave which is not equal to that of natural frequency of the bounded charge and hence the radiation is very weak. The measure of low dielectric loss at various frequencies is also due to dipole rotations. At high frequencies, the orientation polarization ceases and hence the energy need not be spent to rotate dipoles. It is observed from the dielectric studies that the crystal possesses low dielectric constant and low dielectric loss, which is suitable for electro-optic applications. 


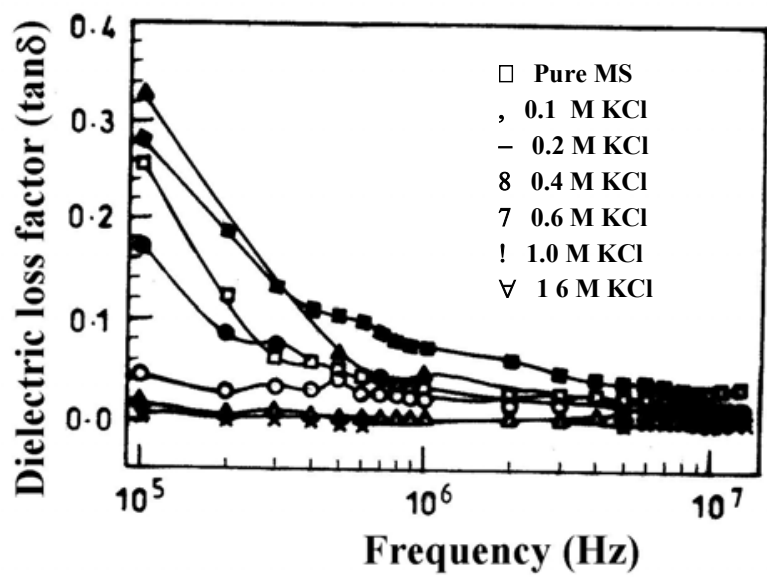

Fig. 7. Dielectric loss as a function of frequency for pure and doped crystals.

\section{CONCLUSIONS}

In this study, pure and $\mathrm{KCl}$ doped epsomite crystals were grown by slow cooling as well as by an isothermal evaporation method. Highly transparent and well faceted large size epsomite single crystals have been grown successfully. The addition of $\mathrm{KCl}$ is found to increase the quality of the crystals. The increasing in the quality of the epsomite crystal in presence of $\mathrm{KCl}$ is due the complexion of trace metal ion by $\mathrm{Cl}^{-}$ion. Lattice parameters for pure crystal are found more or less same and are in good agreement with the ASTM standard data. X-ray study reveals that structures are slightly distorted and adoption of impurities into the crystal lattice. DC conductivity increases in the temperature range of 25-70 ${ }^{\circ} \mathrm{C}$ and also with the $\mathrm{KCl}$ concentration. Dielectric constant is found almost independent of frequency but decreases with the increase in $\mathrm{KCl}$ concentration. The dielectric studies showed that $\mathrm{KCl}$ doped epsomite possesses low dielectric constant and low dielectric loss, which could be suitable for electro-optic applications.

\section{REFERENCES}

1. M. Ikeya, M. G. Hassan, H. Sasaoka, Y. Kinoshita, S. Takaki, C. Yamanaka, Strategy for finding new materials for ESR dosimeters, Appl. Radiat. Isot. 52, 1209, 2000.

2. S. Deminkaya, O. Vural, Z. Gökail, Z. Odabashi, F. Ozdag, E. Erolu and M. Yardim, Norol Bil D, Vol. 15, No. 3, 131-136, 1998.

3. M. Ema, A. Gebrewold, B. T. Altura and B. M. Altura, Report, Department of Physiology, State University of New York, Health Science Centre, Brooklyn, 1998.

4. E. S. Dana, W. E Ford, Crystallography and Physical mineralogy, Wiley Eastern Limited, p 760,1985

5. H. Cano, N. Gabas, J.P. Canselier, Experimental study on the ibuprofen crystal growth morphology in solution., J. Crystal Growth, 224, 335, 2001. 
6. S. Ramalingom, J. Podder, S. N. Kalkura, Crystallization and characterization of orthorhombic MgSO4.7H2O, Cryst. Res. Technol. 36, 12, 1357-1364, 2001.

7. I. A. Kasatkin, Interferometric study of MgSO4. $7 \mathrm{H} 2 \mathrm{O}$ single crystal growth kinetics from solution,.Cryst. Res. Technol. 37, 2-3, 193-205, 2002.

8. G. Sgualdino, G. Vaccari, D. Aquilano and M. Rubbo, Growth kinetics of epsomite $\left(\mathrm{MgSO}_{4}\right.$. $7 \mathrm{H}_{2} \mathrm{O}$ ), J. of Crystal Growth, 83, No. 4, 523-527, 1987.

9. S. A. Jibbouri, C. Strege and J. Ulrich, Crystallization kinetics of epsomite influenced by $\mathrm{pH}$ value and impurities, J. of Crystal Growth, 236, No. 1-3, 400-406, 2002.

10. M. Rubbo, D. Aquilano, and M. F. Angela, Growth morphology of epsomite $\left(\mathrm{MgSO}_{4} \cdot 7 \mathrm{H}_{2} \mathrm{O}\right)$, J. of Crystal Growth, 71, No. 3, 470-482, 1985.

11. S. Ramalingom, J. Podder, S. N. Kalkura and G. Bocelli, Habit modification of epsomite in presence of urea, J. of Crystal Growth, 247, 523-529, 2003.

12. N. Kubota and J. Fukazawa, H. Yashiro, J. W. Mullin, Impurity effect of chromium (III) on the growth and dissolution rates of potassium sulfate crystals, J of Growth, 149, 113, 1995.

Journal of Bangladesh Academy of Sciences, Vol. 33, No. 1, 47-54, 2009 